\title{
On the Behaviour of D-Optimal Exact Designs Under Changing Regression Polynomials
}

\author{
M. P. Iwundu ${ }^{1}$ \& E. B. Albert-Udochukwuka ${ }^{1}$ \\ ${ }^{1}$ Department of Mathematics and Statistics, University of Port Harcourt, Nigeria \\ Correspondence: M. P. Iwundu, Department of Mathematics and Statistics, University of Port Harcourt, Nigeria. \\ E-mail: mary_iwundu@yahoo.com
}

Received: September 1, 2014 Accepted: October 15, 2014 Online Published: October 28, 2014

doi:10.5539/ijsp.v3n4p67

URL: http://dx.doi.org/10.5539/ijsp.v3n4p67

\begin{abstract}
The behaviour of D-optimal exact designs for first order polynomial models under changing regression polynomials is considered. The polynomials, some of which are with or without intercept or with or without interactive term, are defined on design regions that are supported by the points of the Circumscribed Central Composite Design. The best N-point D-optimal exact design for the intercept model (model 1), is the same as the best N-point D-optimal design for the no-intercept model (model 3). Similarly, the best N-point D-optimal design for the intercept model (model 2) is the same as the best N-point D-optimal design for the no-intercept model (model 4), as measured by the determinant values, D-efficiencies, G-efficiencies and Condition numbers. Other N-point designs constructed using the no-intercept models had better determinant values than their corresponding intercept models. The condition numbers indicate that for model 1, the 4-point D-optimal design is orthogonal. For model 2, the 2-point D-optimal exact design and the 4-point D-optimal exact designs are orthogonal. For model 3, the 4-point D-optimal exact design is orthogonal and for model 4, the 4-point D-optimal exact design is orthogonal. Other N-sized designs show less orthogonality. The Equivalence of D-optimality and G-optimality criteria is established for the 4-point design under model 1, for the 2-point and 4-point designs under model 2, for the 4-point design under model 3 and for the 4-point design under model 4.
\end{abstract}

Keywords: D-optimality, exact designs, first order bivariate models, circumscribed central composite design, Defficiencies, G-efficiencies and condition numbers

\section{Introduction}

The importance of first order models in the design of experiments to researchers cannot be over-emphasized as its applications are numerous in industrial processes. In particular, first order models play a vital role in screening experiments for optimum conditions. The first order screening response model

$$
y=\beta_{0}+\beta_{1} x_{1}+\beta_{2} x_{2}+\beta_{12} x_{1} x_{2}+\varepsilon
$$

involves linear effects and a single cross product factor that gives indication of the presence of curvature of the response surface. On the other hand, the first order steepest ascent model

$$
y=\beta_{0}+\beta_{1} x_{1}+\beta_{2} x_{2}+\varepsilon
$$

ignores the cross product term and gives an indication of the absence of curvature of the response surface.

D-optimal design for first order screening response model, defined on the design region supported by points of $3^{2}$ factorial is made up of the four vertex points as these points are the points of maximum variance (Atkinson $\&$ Donev, 1992). For irregular geometric region, Wynn (1970) observed that vertex points constitute the D-optimal designs. In comparing several optimization algorithms used in generating D-optimal designs, Bon (2007) found out that D-optimal designs were significantly more efficient than fractional factorial designs when the number of runs is close to the number of parameters of the model. However, the role of orthogonality in the selection of experimental design was not considered.

In choosing experimental designs in which regression models are assumed, there is the need for a choice of optimality criteria and associated numerical techniques that provide objective methods for selecting design points 
that are optimal. According to Atkinson and Donev (1992) an ideal design is one that would minimize the generalized variance of the parameter estimates and minimize the variance of predicted model over the design region. Some design criteria, which relate to these properties include, the D-Optimality criterion, G-Optimality criterion, A-Optimality criterion, V-Optimality criterion, E-Optimality criterion, etc. However, the D-optimality criterion has been extensively used in the literature.

Two desirable characteristics of any design are orthogonality and rotatability. Technically, two columns in a design matrix are orthogonal if the sum of the products of their elements within each row is equal to zero. In practice, one may encounter situations where the columns of the design matrix are not completely orthogonal but the more orthogonal the columns are, the better the design. Rotatability, on the other hand, bothers on how best to extract the maximum amount of (unbiased) information from the design, or specifically, from the experimental region of interest. For more on the characteristics, see, Khuri and Cornell (1987) and Montgomery (1997).

Although much of the literature in optimal design of experiments assume the regression model is a full polynomial model, models with improper polynomial regression functions having some terms missing also exist (Huang et al., 1995; Bon, 2007). The focus of this work is to investigate properties of D-optimal designs for first order models under changing regression models and to establish the equivalence of D-Optimality and G-Optimality criteria. In particular, we consider the screening response model in (i), the steepest ascent model in (ii) as well as the no-intercept models

$$
y=\beta_{1} x_{1}+\beta_{2} x_{2}+\beta_{12} x_{1} x_{2}+\varepsilon
$$

and

$$
y=\beta_{1} x_{1}+\beta_{2} x_{2}+\varepsilon
$$

The polynomials, some of which are with or without intercept or with or without interactive term, are defined on design regions that are supported by the points of the Circumscribed Central Composite Design. In investigating the behaviour of D-optimal exact designs for the first order polynomial models D-efficiencies, G-efficiencies and Condition numbers shall be used as measures of assessment.

\section{Method}

We present definition of basic concepts that are used in this work as well as the underlying methodology.

\subsection{Definition of Basic Concepts}

\subsubsection{Exact Design}

An exact design for a specified design size, $\mathrm{N}$, is a measure $\xi_{N}=\left\{\begin{array}{l}\frac{x_{1}}{1}, \frac{x_{2}}{2}, \ldots \frac{x_{n}}{N}, \frac{r_{1}}{N}, \ldots \frac{r_{n}}{N}\end{array}\right\}$, where $r_{i}$ is the integer number of experimental runs or trails at $\underline{x_{i}}, \sum_{i=1}^{n} \frac{r_{i}}{N}=1$ and $N=\sum_{i=1}^{n} r_{i}$.

\subsubsection{D-Optimality Criterion}

D-optimality criterion is an optimality criterion that maximizes the determinant value of information matrix of design over a the design space. A design, $\xi_{\mathrm{N}}^{*}$, is called an N-point D-optimal exact design if and only if $\left|M\left(\xi_{\mathrm{N}}^{*}\right)\right|$ $=\max \left|M\left(\xi_{\mathrm{N}}\right)\right|$ among all possible designs $\xi_{N}$ in the design space, $\widetilde{\mathrm{X}}$, where $M\left(\xi_{N}\right)=\mathrm{X}^{\prime} \mathrm{X}$ and normalized as $\frac{1}{N}\left(\mathrm{X}^{\prime} \mathrm{X}\right)$. The matrix $X$ is called the design matrix or extended design matrix associated with $\xi_{N}$. A D-optimal design emphasizes the precision of the estimated coefficients of the assumed model, Box and Behnken (1960). Doptimal designs are generally generated by search algorithms and seek to minimize the variances and co-variances of the parameter estimates for a specified model.

\subsubsection{G-Optimality Criterion}

G-Optimality Criterion deals with the variance of prediction of the candidate points in the design region. The selected optimal design by G-optimality criterion is chosen to minimize the highest variance of prediction in the design, where the variance of prediction at a design point $\underline{x}$ is defined by $\operatorname{var}\{y(\underline{x})\}=\underline{\mathrm{x}}^{\prime} \mathrm{M}^{-1} \underline{\mathrm{x}}$, Onukogu (1997).

\subsubsection{Equivalent Design}

According to Atkinson and Donev (1992), the equivalence of D-Optimality and G-Optimality criteria exists when an optimal design that maximizes the determinant of the information matrix also minimizes the maximum variance of the predicted response. 


\subsubsection{D-Efficiency}

According to Atkinson and Donev (1992), D-efficiency of an arbitrary design, $\xi_{\mathrm{N}}$ is defined as

$$
D_{\text {eff }}=\left\{\frac{\mathrm{M}\left(\xi_{\mathrm{N}}\right)}{\mathrm{M}\left(\xi_{\mathrm{N}}^{*}\right)}\right\}
$$

\subsubsection{G-Efficiency}

According to Atkinson and Donev (1992), G-efficiency of a design, $\xi_{\mathrm{N}}$ is defined as

$$
G_{\text {eff }}=\frac{\mathrm{d}\left(\xi_{\mathrm{N}}^{*}\right)}{\mathrm{d}\left(\xi_{\mathrm{N}}\right)}=\frac{\mathrm{p}}{\mathrm{d}\left(\xi_{\mathrm{N}}\right)}
$$

where $\mathrm{d}\left(\xi_{\mathrm{N}}^{*}\right)$ is the maximun variance of predicted response for $\xi_{\mathrm{N}}^{*}$ and $d\left(\xi_{\mathrm{N}}\right)$ is the maximun variance of predicted response for $\xi_{\mathrm{N}}$.

\subsubsection{Condition Number}

The condition number is an evaluation criteria like the G-efficiency and is used to rate an already created Doptimal design. It evaluates the sphericity and the symmetry of the D-optimal design (Eriksson et al., 2000, p. 220). Condition number is always greater or equal to 1 and a design with a condition number of 1 is orthogonal, while an increasing condition number indicates a less orthogonal design. By definition, the condition number of a square symmetric matrix

$$
A=\left(\begin{array}{ccc}
a_{11} & \cdots & a_{1 n} \\
\vdots & \ddots & \vdots \\
a_{1 n} & \cdots & a_{n n}
\end{array}\right)
$$

is the product of the norm of $A$ and the norm of $A$-inverse, written as,

$$
k=\|A\|\left\|A^{-1}\right\|
$$

where the norm of $A$ is defined as

$$
\|A\|=\max _{1 \leq j \leq n} \sum_{i=1}^{n}\left|a_{i j}\right|
$$

and the norm of $A^{-1}$ is similarly defined.

\subsubsection{Orthogonal Designs}

One desirable characteristic of any design is that the main effect and interaction estimates of interest are independent of each other. Technically, two columns in a design matrix are orthogonal if the sum of the products of their elements within each row is equal to zero. In practice, one may encounter situations where the columns of the design matrix are not completely orthogonal. In general, the more orthogonal the columns are, the better the design. Hence, a design is said to be orthogonal if the assocaiated information matrix is a diagonal matrix. For such designs, the model parameters are uncorrelated.

\subsection{Methodology}

The algorithm to be used in the construction of the exact designs requires $25 \%$ search on the available designs within a design class and can be seen in Albert-Udochukwuka (2014). It is a combinatorial algorithm like that of Onukogu and Iwundu (2007) but reduces the required number of determinant evaluations to about $25 \%$ of the total possible evaluations within a design class. The N-point designs are to be constructed to lie in the interval $p \leq N \leq \frac{1}{2} p(p+1)+1$. The grouping of support points in $\tilde{X}$ shall be as in the combinatorial procedure of Onukogu and Iwundu (2007). The initial tuple of support points shall be according to the rules of Iwundu (2010), which allow the initial design to be as close as possible to the D-optimal design, as measured by the determinant values of information matrices, thereby reducing the number of iterations required to reach the optimal value. The concepts of D-efficiency, G-efficiency and condition number shall be employed in assessing the goodness of the designs. Moreover, these concepts shall be applied to the designs under changing regression polynomials.

\section{Results}

We present illustrations using the four models defined in section 1. Particularly, we consider obtaining N-point D-optimal exact designs for the first order models, defined in equations (i)-(iv), on the design region supported 
by design points of the Circumscribed Central Composite design. The choice of the design region supported by design points of the Circumscribed Central Composite design is motivated by the study of Iwundu and Otaru (2014) on imposing D-optimality criterion on the design regions of the Central Composite Designs. Results of the study revealed that D-optimal exact designs defined on the design region supported by the design points of the Circumscribed Central Composite design had better determinant values of information matrices. The geometric region of the Circumscribed Central Composite design is as in Figure 1.

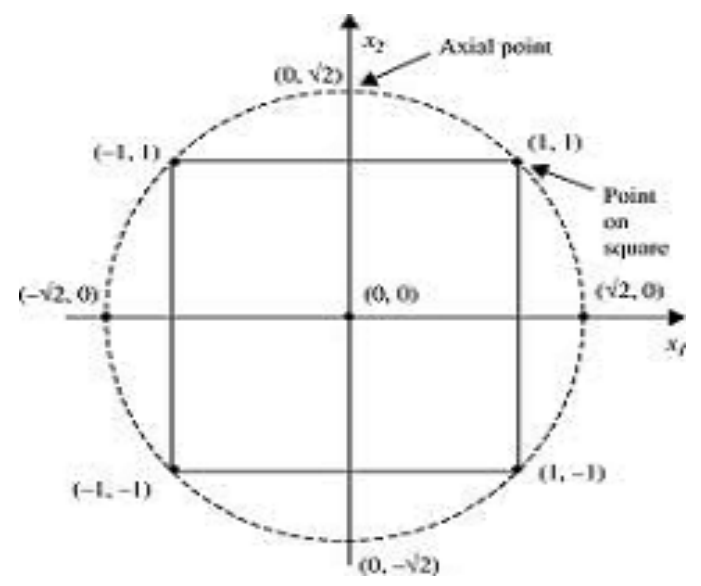

Figure 1. Geometric region supported by points of Circumscribed CCD

Following the combinatorial procedure of Onukogu and Iwundu $(2007)$ the design points, $\{(1,1),(1,-1),(-1,1)$, $(-1,-1),(1.414,0),(-1.414,0),(0,1.414),(0,-1.414),(0,0)\}$, that make up the design region, are arranged into three groups according to their distances from the center of the design region as

$\mathrm{g}_{1}:\{(1,1),(1,-1),(-1,1),(-1,-1)\}$

$\mathrm{g}_{2}:\{(1.414,0),(-1.414,0),(0,1.414),(0,-1.414)\}$

$\mathrm{g}_{3}:\{(0,0)\}$.

\subsection{Illustrations Using Model 1}

For the model

$$
y=\beta_{0}+\beta_{1} x_{1}+\beta_{2} x_{2}+\beta_{12} x_{1} x_{2}+\varepsilon
$$

we shall constuct $\mathrm{N}$-point $\mathrm{D}$-optimal exact design; $\mathrm{N}=4, \ldots, 11$.

For $\mathrm{N}=4$, the initial tuple of support points is [4:0:0]. With this, we commence the search for D-optimal exact design as summarized in Table 1 .

Table 1. Combinatorics for a 4-point D-optimal exact design model 1

\begin{tabular}{ccccccc}
\hline Step & $\mathrm{g}_{1}$ & $\mathrm{~g}_{2}$ & $\mathrm{~g}_{3}$ & $\begin{array}{l}\text { Total Number of } \\
\text { Available Designs }\end{array}$ & $\begin{array}{l}\text { Best Determinant } \\
\text { Value }\end{array}$ & $\begin{array}{l}\text { Max Number of De- } \\
\text { signs to Investigate }\end{array}$ \\
\hline 0 & 4 & 0 & 0 & 1 & 1.0000 & 1 \\
1 & 3 & 1 & 0 & 16 & 0.3642 & 4 \\
2 & 3 & 0 & 1 & 4 & 0.0625 & 1 \\
\hline \multicolumn{2}{l}{ TOTAL } & & 21 & & 6 \\
\hline
\end{tabular}

The maximum determinant value is det $*=1.0000$ and it is associated with design class [4:0:0] having the design points $\{(-11,1-1,11,-1-1)\}$. Within the class [4:0:0], the number of D-optimal exact design is 1 .

For $\mathrm{N}=5$, the initial tuple of support points is [4:1:0]. With this, we commence the search for D-optimal exact design as summarized in Table 2. 
Table 2. Combinatorics for a 5-point D-optimal exact design for model 1

\begin{tabular}{|c|c|c|c|c|c|c|}
\hline Step & $\mathrm{g}_{1}$ & $\mathrm{~g}_{2}$ & $\mathrm{~g}_{3}$ & $\begin{array}{l}\text { Total Number of } \\
\text { Available Designs }\end{array}$ & $\begin{array}{l}\text { Best Determinant } \\
\text { Value }\end{array}$ & $\begin{array}{l}\text { Max Number of De- } \\
\text { signs to Investigate }\end{array}$ \\
\hline 0 & 4 & 1 & 0 & 4 & 0.7167 & 1 \\
\hline 1 & 4 & 0 & 1 & 1 & 0.5120 & 1 \\
\hline 2 & 5 & 0 & 0 & 4 & 0.8192 & 1 \\
\hline \multicolumn{2}{|c|}{ TOTAL } & & & 9 & & 3 \\
\hline
\end{tabular}

The maximum determinant value is det $*=8.192 \times 10^{-1}$ and it is associated with design class [5:0:0] having the design points $\{(-11,-1-1,11,-1-1,11)$ or $(-11,1-1,11,-1-1,1-1)$ or $(-11,1-1,11,-1-1,-1-1)$ or $(-11,1-1,11,-1-1$, $-11)\}$. Within the class [5:0:0], the number of D-optimal exact designs is 4 .

For $\mathrm{N}=6$, the initial tuple of support points is [4:1:1]. With this, we commence the search for D-optimal exact design as summarized in Table 3.

Table 3. Combinatorics for a 6-point D-optimal exact design for model 1

\begin{tabular}{ccccccc}
\hline Step & $\mathrm{g}_{1}$ & $\mathrm{~g}_{2}$ & $\mathrm{~g}_{3}$ & $\begin{array}{l}\text { Total Number of } \\
\text { Available Designs }\end{array}$ & $\begin{array}{l}\text { Best Determinant } \\
\text { Value }\end{array}$ & $\begin{array}{l}\text { Max Number of De- } \\
\text { signs to Investigate }\end{array}$ \\
\hline 0 & 4 & 1 & 1 & 4 & 0.4197 & 1 \\
1 & 4 & 0 & 2 & 1 & 0.2963 & 1 \\
2 & 4 & 2 & 0 & 6 & 0.5925 & 6 \\
3 & 5 & 1 & 0 & 16 & 0.6892 & 6 \\
4 & 6 & 0 & 0 & 6 & 0.7901 & 4 \\
5 & 3 & 2 & 0 & 16 & 0.3660 & 6 \\
6 & 3 & 2 & 1 & 24 & 0.2621 & 28 \\
\hline \multicolumn{7}{l}{ TOTAL } \\
\hline
\end{tabular}

The maximum determinant value is det $*=7.901 \times 10^{-1}$ and it is associated with design class [6:0:0] having the design points $\{(-11,1-1,11,-1-1,-11-1-1)$ or $(-11,1-1,11,-1-1,-11,11)$ or $(-11,1-1,11,-1-1,-11,-1-1)$ or $(-11$, $1-1,11,-1-1,1-1,11)$ or $(-11,1-1,11,-1-1,1-1,-1-1)$ or $(-11,1-1,11,-1-1,11,-1-1)\}$. Within the class [6:0:0], the number of D-optimal exact designs is 6.

For $\mathrm{N}=7$, the initial tuple of support points is [5:1:1]. With this, we commence the search for D-optimal exact design as summarized in Table 4.

Table 4. Combinatorics for a 7-point D-optimal exact design for model 1

\begin{tabular}{llllccc}
\hline Step & $\mathrm{g}_{1}$ & $\mathrm{~g}_{2}$ & $\mathrm{~g}_{3}$ & $\begin{array}{l}\text { Total Number of } \\
\text { Available Designs }\end{array}$ & $\begin{array}{l}\text { Best Determinant } \\
\text { Value }\end{array}$ & $\begin{array}{l}\text { Max Number of De- } \\
\text { signs to Investigate }\end{array}$ \\
\hline 0 & 5 & 1 & 1 & 16 & 0.4386 & 4 \\
1 & 5 & 0 & 2 & 4 & 0.3065 & 1 \\
2 & 5 & 2 & 0 & 24 & 0.6362 & 6 \\
3 & 6 & 0 & 1 & 6 & 0.5065 & 6 \\
4 & 6 & 1 & 0 & 24 & 0.7417 & 6 \\
5 & 7 & 0 & 0 & 4 & 0.8530 & 1 \\
6 & 4 & 3 & 0 & 4 & 0.5330 & 6 \\
7 & 4 & 2 & 1 & 6 & 0.3798 & 1 \\
8 & 3 & 4 & 0 & 4 & 0.3197 & 4 \\
9 & 3 & 1 & 1 & 16 & 0.2342 & 6 \\
10 & 2 & 4 & 1 & 6 & 0.1332 & 42 \\
\hline \multicolumn{7}{l}{ TOTAL } \\
\hline \multicolumn{7}{c}{}
\end{tabular}

The maximum determinant value is $\operatorname{det} *=8.530 \times 10^{-1}$ and it is associated with design class [7:0:0] having the design points $\{(-11,1-1,11,-1-1,11,1-1,11)$ or $(-11,1-1,11,-1-1,-11,1-1,-1-1)$ or $(-11,1-1,11,-1-1,-11,11$, $-1-1)$ or $(-11,-1-1,11,-1-1,1-1,11,-1-1)\}$. Within the class [7:0:0], the number of D-optimal exact designs is 4 . 
For $\mathrm{N}=8$, the initial tuple of support points is [5:2:1]. With this, we commence the search for D-optimal exact design as summarized in Table 5 .

Table 5. Combinatorics for an 8-point D-optimal exact design for model 1

\begin{tabular}{ccccccc}
\hline Step & $\mathrm{g}_{1}$ & $\mathrm{~g}_{2}$ & $\mathrm{~g}_{3}$ & $\begin{array}{l}\text { Total Number of } \\
\text { Available Designs }\end{array}$ & $\begin{array}{l}\text { Best Determinant } \\
\text { Value }\end{array}$ & $\begin{array}{l}\text { Max Number of De- } \\
\text { signs to Investigate }\end{array}$ \\
\hline 0 & 5 & 2 & 1 & 24 & 0.4286 & 6 \\
1 & 5 & 1 & 2 & 16 & 0.2962 & 4 \\
2 & 5 & 3 & 0 & 16 & 0.5532 & 4 \\
3 & 6 & 2 & 0 & 36 & 0.6603 & 6 \\
4 & 7 & 1 & 0 & 16 & 0.7785 & 4 \\
5 & 8 & 0 & 0 & 1 & 1.0000 & 1 \\
6 & 4 & 4 & 0 & 1 & 0.4998 & 1 \\
7 & 4 & 3 & 1 & 4 & 0.3593 & 1 \\
\hline \multicolumn{2}{l}{ Total } & & & & & 27 \\
\hline
\end{tabular}

The maximum determinant value is $\operatorname{det} *=1.0000$ and it is associated with design class [8:0:0] having the design points $\{(-11,1-1,11,-1-1,-11,1-1,11,-1-1)\}$. Within the class [8:0:0], the number of D-optimal exact designs is 1.

For $\mathrm{N}=9$, the initial tuple of support points is [5:3:1]. With this, we commence the search for D-optimal exact design as summarized in Table 6 .

Table 6. Combinatorics for a 9-point D-optimal exact design for model 1

\begin{tabular}{llllccc}
\hline Step & $\mathrm{g}_{1}$ & $\mathrm{~g}_{2}$ & $\mathrm{~g}_{3}$ & $\begin{array}{c}\text { Total Number of } \\
\text { Available Designs }\end{array}$ & $\begin{array}{l}\text { Best Determinant } \\
\text { Value }\end{array}$ & $\begin{array}{l}\text { Max Number of De- } \\
\text { signs to Investigate }\end{array}$ \\
\hline 0 & 5 & 3 & 1 & 16 & 0.3905 & 4 \\
1 & 5 & 2 & 2 & 24 & 0.3023 & 6 \\
2 & 5 & 4 & 0 & 4 & 0.5071 & 1 \\
3 & 6 & 3 & 0 & 24 & 0.6115 & 6 \\
4 & 7 & 2 & 0 & 24 & 0.7273 & 6 \\
5 & 8 & 1 & 0 & 4 & 0.8584 & 1 \\
6 & 9 & 0 & 0 & 4 & 0.9364 & 1 \\
7 & 4 & 5 & 0 & 4 & 0.4291 & 1 \\
8 & 4 & 4 & 1 & 1 & 0.5623 & 1 \\
\hline \multicolumn{7}{l}{ Total } \\
\hline
\end{tabular}

The maximum determinant value is $\operatorname{det} *=9.364 \times 10^{-1}$ and it is associated with design class [9:0:0] having the design points $\{(-11,1-1,11,-1-1,-11,1-1,11,-1-1,11)$ or $(-11,1-1,11,-1-1,-11,1-1,11,-1-1,1-1)$ or $(-11$, $1-1,11,-1-1,-11,1-1,11,-1-1,11)$, or $(-11,1-1,11,-1-1,-11,1-1,11,-1-1,-1-1)\}$. Within the class [9:0:0], the number of D-optimal exact designs is 4.

For $\mathrm{N}=10$, the initial tuple of support points is [5:3:2]. With this, we commence the search for D-optimal exact design as summarized in Table 7 . 
Table 7. Combinatorics for a 10-point D-optimal exact design for model 1

\begin{tabular}{llllccc}
\hline Step & $\mathrm{g}_{1}$ & $\mathrm{~g}_{2}$ & $\mathrm{~g}_{3}$ & $\begin{array}{c}\text { Total Number of } \\
\text { Available Designs }\end{array}$ & $\begin{array}{l}\text { Best Determinant } \\
\text { Value }\end{array}$ & $\begin{array}{l}\text { Max Number of De- } \\
\text { signs to Investigate }\end{array}$ \\
\hline 0 & 5 & 3 & 2 & 16 & 0.2858 & 4 \\
1 & 5 & 2 & 3 & 24 & 0.2211 & 6 \\
2 & 5 & 4 & 1 & 4 & 0.3711 & 1 \\
3 & 5 & 5 & 0 & 16 & 0.4569 & 4 \\
4 & 6 & 4 & 0 & 6 & 0.5375 & 6 \\
5 & 7 & 3 & 0 & 16 & 0.6462 & 4 \\
6 & 8 & 2 & 0 & 6 & 0.7679 & 6 \\
7 & 9 & 1 & 0 & 16 & 0.8437 & 6 \\
8 & 10 & 0 & 0 & 6 & 0.9216 & 6 \\
9 & 4 & 6 & 0 & 6 & 0.3839 & 1 \\
10 & 4 & 5 & 1 & 4 & 0.3135 & 48 \\
\hline \multicolumn{7}{l}{ TOTAL }
\end{tabular}

The maximum determinant value is $\operatorname{det} *=9.216 \times 10^{-1}$ and it is associated with design class [10:0:0] having the design points $\{(-11,1-1,11,-1-1,-11,1-1,11,-1-1,-11,1-1)$ or $(-11,1-1,11,-1-1,-11,1-1,11,-1-1,-11,11)$ or $(-11,1-1,11,-1-1,-11,1-1,11,-1-1,-11,-1-1)$ or $(-11,1-1,11,-1-1,-11,1-1,11,-1-1,1-1,1)$ or $(-11,1-1,11$, $-1-1,-11,1-1,11,-1-1,1-1,-1-1)$ or $(-11,1-1,11,-1-1,-11,1-1,11,-1-1,11,-1-1)\}$. Within the class [10:0:0], the number of D-optimal exact designs is 6.

For $\mathrm{N}=11$, the initial tuple of support points is [5:4:2]. With this, we commence the search for D-optimal exact design as summarized in Table 8.

Table 8. Combinatorics for an 11-point D-optimal exact design for model 1

\begin{tabular}{|c|c|c|c|c|c|c|}
\hline Step & $\mathrm{g}_{1}$ & $\mathrm{~g}_{2}$ & $\mathrm{~g}_{3}$ & $\begin{array}{l}\text { Total Number of } \\
\text { Available Designs }\end{array}$ & $\begin{array}{l}\text { Best Determinant } \\
\text { Value }\end{array}$ & $\begin{array}{l}\text { Max Number of De- } \\
\text { signs to Investigate }\end{array}$ \\
\hline 0 & 5 & 4 & 2 & 4 & 0.2797 & 1 \\
\hline 1 & 5 & 5 & 1 & 16 & 0.3443 & 4 \\
\hline 2 & 5 & 6 & 0 & 24 & 0.4251 & 6 \\
\hline 3 & 5 & 3 & 3 & 16 & 0.2154 & 4 \\
\hline 4 & 6 & 5 & 0 & 24 & 0.5034 & 6 \\
\hline 5 & 7 & 4 & 0 & 4 & 0.5810 & 1 \\
\hline 6 & 8 & 3 & 0 & 4 & 0.7080 & 1 \\
\hline 7 & 9 & 2 & 0 & 24 & 0.7849 & 6 \\
\hline 8 & 10 & 1 & 0 & 24 & 0.8632 & 6 \\
\hline 9 & 11 & 0 & 0 & 4 & 0.9442 & 1 \\
\hline 19 & 4 & 7 & 0 & 4 & 0.3539 & 1 \\
\hline 11 & 4 & 6 & 1 & 6 & 0.2895 & 6 \\
\hline \multicolumn{2}{|c|}{ TOTAL } & & & 154 & & 43 \\
\hline
\end{tabular}

The maximum determinant value is det $*=9.442 \times 10^{-1}$ and it is associated with design class [11:0:0] having the design points $\{(-11,1-1,11,-1-1,-11,1-1,11,-1-1,-11,1-1,11)$ or $(-11,1-1,11,-1-1,-11,1-1,11,-1-1,-11$, $1-1,-1-1)$ or $(-11,1-1,11,-1-1,-11,1-1,11,-1-1,-11,11,-1-1)$ or $(-11,1-1,11,-1-1,-11,1-1,11,-1-1,1-1,11$, $-1-1)\}$. Within the class [11:0:0], the number of D-optimal exact designs is 4 .

\subsection{Illustrations Using Model 2}

For the model

$$
y=\beta_{0}+\beta_{1} x_{1}+\beta_{2} x_{2}+\varepsilon
$$

we shall constuct $\mathrm{N}$-point $\mathrm{D}$-optimal exact design; $\mathrm{N}=3, \ldots, 7$.

For $\mathrm{N}=3$, the initial tuple of support points is [3:0:0]. With this, we commence the search for D-optimal exact design as summarized in Table 9. 
Table 9. Combinatorics for a 3-point D-optimal exact design for model 2

\begin{tabular}{ccccccc}
\hline Step & $\mathrm{g}_{1}$ & $\mathrm{~g}_{2}$ & $\mathrm{~g}_{3}$ & $\begin{array}{l}\text { Total Number of } \\
\text { Available Designs }\end{array}$ & $\begin{array}{l}\text { Best Determinant } \\
\text { Value }\end{array}$ & $\begin{array}{l}\text { Max Number of De- } \\
\text { signs to Investigate }\end{array}$ \\
\hline 0 & 3 & 0 & 0 & 4 & 0.5926 & 4 \\
1 & 2 & 1 & 0 & 24 & 0.8633 & 6 \\
2 & 2 & 0 & 1 & 6 & 0.1481 & 6 \\
3 & 1 & 2 & 0 & 24 & 0.8631 & 6 \\
4 & 1 & 1 & 1 & 16 & 0.0741 & 4 \\
\hline \multicolumn{7}{l}{ TOTAL } \\
\multicolumn{7}{r}{} \\
\multicolumn{7}{r}{} \\
\hline
\end{tabular}

The maximum determinant value is det $*=8.633 \times 10^{-1}$ and it is associated with design class [2:1:0] having the design points $\left\{(-11),\left(\begin{array}{ll}1 & 1\end{array}\right),(0-1.414)\right.$ or $(-11),(-1-1),(1.4140)$ or $(1-1),(11),(-1.4140)$ or $(1-1),(-1-1),(0$ 1.414)\}. Within the class [2:1:0], the number of D-optimal exact designs is 4.

For $\mathrm{N}=4$, the initial tuple of support points is [3:1:0]. With this, we commence the search for D-optimal exact design as summarized in Table 10.

Table 10. Combinatorics for a 4-point D-optimal exact design for model 2

\begin{tabular}{ccccccc}
\hline Step & $\mathrm{g}_{1}$ & $\mathrm{~g}_{2}$ & $\mathrm{~g}_{3}$ & $\begin{array}{l}\text { Total Number of } \\
\text { Available Designs }\end{array}$ & $\begin{array}{l}\text { Best Determinant } \\
\text { Value }\end{array}$ & $\begin{array}{l}\text { Max Number of De- } \\
\text { signs to Investigate }\end{array}$ \\
\hline 0 & 3 & 1 & 0 & 16 & 0.8017 & 4 \\
1 & 3 & 0 & 1 & 4 & 0.3750 & 1 \\
2 & 4 & 0 & 0 & 1 & 1.0000 & 1 \\
3 & 2 & 2 & 0 & 36 & 0.8533 & 9 \\
4 & 2 & 1 & 1 & 24 & 0.4892 & 6 \\
\hline \multicolumn{2}{l}{ TOTAL } & & 81 & & 21 \\
\hline
\end{tabular}

The maximum determinant value is det $*=1.0000$ and it is associated with design class [4:0:0] having the design points $\{(-11),(1-1),(11),(-1-1)\}$. Within the class [4:0:0] the number of D-optimal exact design is 1 .

For $\mathrm{N}=5$, the initial tuple of support points is [3:1:1]. With this, we commence the search for D-optimal exact design as summarized in Table 11.

Table 11. Combinatorics for a 5-point D-optimal exact design for model 2

\begin{tabular}{ccccccc}
\hline Step & $\mathrm{g}_{1}$ & $\mathrm{~g}_{2}$ & $\mathrm{~g}_{3}$ & $\begin{array}{l}\text { Total Number of } \\
\text { Available Designs }\end{array}$ & $\begin{array}{l}\text { Best Determinant } \\
\text { Value }\end{array}$ & $\begin{array}{l}\text { Max Number of De- } \\
\text { signs to Investigate }\end{array}$ \\
\hline 0 & 3 & 1 & 1 & 16 & 0.5224 & 4 \\
1 & 3 & 0 & 2 & 4 & 0.2560 & 1 \\
2 & 3 & 2 & 0 & 24 & 0.9433 & 6 \\
3 & 4 & 1 & 0 & 4 & 0.8959 & 1 \\
4 & 2 & 3 & 0 & 24 & 0.9432 & 6 \\
5 & 2 & 2 & 1 & 36 & 0.5648 & 9 \\
\hline \multicolumn{2}{l}{ TOTAL } & \multicolumn{1}{l}{} \\
\hline
\end{tabular}

The maximum determinant value is det $*=9.433 \times 10^{-1}$ and it is associated with design class [3:2:0] having the design points $\{(-11,1-1,11,-1.4140,0-1.414)$ or $(-11,1-1,-1-1,01.414,1.4140)$ or $(-11,11,-1-1,1.414,0$ $-1.414)$ or $(1-1,11,-1-1,01.414,-1.4140)\}$. Within the class [3:2:0] the number of D-optimal exact designs is 4 .

For $\mathrm{N}=6$ the initial tuple of support points is [3:2:1]. With this, we commence the search for D-optimal exact design as summarized in Table 12. 
Table 12. Combinatorics for a 6-point D-optimal exact design for model 2

\begin{tabular}{ccccccc}
\hline Step & $\mathrm{g}_{1}$ & $\mathrm{~g}_{2}$ & $\mathrm{~g}_{3}$ & $\begin{array}{l}\text { Total Number of } \\
\text { Available Designs }\end{array}$ & $\begin{array}{l}\text { Best Determinant } \\
\text { Value }\end{array}$ & $\begin{array}{l}\text { Max Number of De- } \\
\text { signs to Investigate }\end{array}$ \\
\hline 0 & 3 & 2 & 1 & 24 & 0.6570 & 6 \\
1 & 3 & 3 & 0 & 16 & 0.9193 & 4 \\
2 & 3 & 1 & 2 & 16 & 0.3671 & 4 \\
3 & 4 & 2 & 0 & 6 & 0.8888 & 6 \\
4 & 2 & 4 & 0 & 6 & 0.8885 & 6 \\
5 & 2 & 3 & 1 & 24 & 0.6569 & 6 \\
\hline \multicolumn{2}{l}{ TOTAL } & & 92 & & 32 \\
\hline
\end{tabular}

The maximum determinant value is det $*=9.193 \times 10^{-1}$ and it is associated with design class [3:3:0] having the design points $\{(1-11,1-1,11,01.414,1.4140,0-1.414)$ or $(-11,1-1,11,1.4140,-1.4140,0-1.414)$ or $(-11$, $1-1,-1-1,01.1414,1.4140,-1.4140)$ or $(-11,1-1,-1-1,01.1414,1.4140,0-1.414)$ or $(-11,11,-1-1,0-1.414,0$ $1.414,1.4140)$ or $(-11,11,-1-1,1.4140,-1.4140,0-1.414)$ or $(1-1,11,-1-1,01.414,1.4140,-1.4140)$ or $(1-1$, $11,-1-1,01.414,-1.4140,0-1.414)\}$. Within the class [3:3:0] the number of D-optimal exact designs is 6.

For $\mathrm{N}=7$ the initial tuple of support points is [3:3:1]. With this, we commence the search for D-optimal exact design as summarized in Table 13.

Table 13. Combinatorics for a 7-point D-optimal exact design for model 2

\begin{tabular}{ccccccc}
\hline Step & $\mathrm{g}_{1}$ & $\mathrm{~g}_{2}$ & $\mathrm{~g}_{3}$ & $\begin{array}{c}\text { Total Number of } \\
\text { Available Designs }\end{array}$ & $\begin{array}{l}\text { Best Determinant } \\
\text { Value }\end{array}$ & $\begin{array}{l}\text { Max Number of De- } \\
\text { signs to Investigate }\end{array}$ \\
\hline 0 & 3 & 3 & 1 & 16 & 0.6780 & 4 \\
1 & 3 & 2 & 2 & 24 & 0.4837 & 6 \\
2 & 3 & 4 & 0 & 4 & 0.9326 & 1 \\
3 & 4 & 3 & 0 & 4 & 0.9327 & 1 \\
4 & 5 & 2 & 0 & 24 & 0.9734 & 6 \\
5 & 6 & 1 & 0 & 24 & 0.9735 & 6 \\
6 & 7 & 0 & 0 & 4 & 0.9329 & 6 \\
7 & 2 & 5 & 0 & 24 & 0.9732 & 6 \\
8 & 2 & 4 & 1 & 6 & 0.6644 & 37 \\
\multicolumn{2}{l}{ TOTAL } & & 130 & &
\end{tabular}

The maximum determinant value is det $*=9.735 \times 10^{-1}$ and it is associated with design class [6:1:0] having the design points $\{(-11,1-1,11,-1-1,-11,11,0-1.414)$ or $(-11,1-1,11,-1-1,-11,-1-1,1.14140)$ or $(-11,-1-1,11,-1-$ $1,1-1,11,-1.4140)$ or $(-11,1-1,11,-1-1,1-1,-1-1,01.1414)\}$. Within the class $[6: 1: 0]$ the number of D-optimal exact designs is 4 .

\subsection{Illustrations Using Model 3}

For the model

$$
y=\beta_{1} x_{1}+\beta_{2} x_{2}+\beta_{12} x_{1} x_{2}+\varepsilon
$$

we shall constuct $\mathrm{N}$-point $\mathrm{D}$-optimal exact design; $\mathrm{N}=3, \ldots, 7$.

For $\mathrm{N}=3$, the initial tuple of support points is [3:0:0]. With this, we commence the search for D-optimal exact design as summarized in Table 14.

Table 14. Combinatorics for a 3-point D-optimal exact design for model 3

\begin{tabular}{ccccccc}
\hline Step & $\mathrm{g}_{1}$ & $\mathrm{~g}_{2}$ & $\mathrm{~g}_{3}$ & $\begin{array}{l}\text { Number of Avail- } \\
\text { able Designs }\end{array}$ & $\begin{array}{l}\text { Best Determinant } \\
\text { Value }\end{array}$ & $\begin{array}{l}\text { Max Number of De- } \\
\text { signs to Investigate }\end{array}$ \\
\hline 0 & 3 & 0 & 0 & 4 & 0.5926 & 4 \\
1 & 2 & 1 & 0 & 24 & 0.2962 & 6 \\
2 & 2 & 0 & 1 & 6 & 0.0000 & 6 \\
\hline \multicolumn{7}{l}{ TOTAL } \\
\hline
\end{tabular}


The maximum determinant value is det $*=5.926 \times 10^{-1}$ and it is associated with design class [3:0:0] having the design points $\{(-11,1-1,11)$ or $(-11,11,-1-1)$ or $(-11,1-1,-1-1)$ or $(1-1,11,-1-1)\}$. Within the class [3:0:0], the number of D-optimal exact designs is 4 .

For $\mathrm{N}=4$, the initial tuple of support points is [3:1:0]. With this, we commence the search for the D-optimal exact design as summarized in Table 15.

Table 15. Combinatorics for a 4-point D-optimal exact design for model 3

\begin{tabular}{ccccccc}
\hline Step & $\mathrm{g}_{1}$ & $\mathrm{~g}_{2}$ & $\mathrm{~g}_{3}$ & $\begin{array}{l}\text { Number of Avail- } \\
\text { able Designs }\end{array}$ & $\begin{array}{l}\text { Best Determinant } \\
\text { Value }\end{array}$ & $\begin{array}{l}\text { Max Number of De- } \\
\text { signs to Investigate }\end{array}$ \\
\hline 0 & 3 & 1 & 0 & 16 & 0.4999 & 4 \\
1 & 3 & 0 & 1 & 4 & 0.2500 & 1 \\
2 & 4 & 0 & 0 & 1 & 1.0000 & 1 \\
\hline \multicolumn{2}{l}{ TOTAL } & & 21 & & 6 \\
\hline
\end{tabular}

The maximum determinant value is $\operatorname{det} *=1.000$ and it is associated with design class [4:0:0] having the design points $\{(-11,1-1,11,-1-1)\}$. Within the class [3:1:0], the number of D-optimal exact designs is 1 .

For $\mathrm{N}=5$, the initial tuple of support points is [3:1:1]. With this, we commence the search for the D-optimal exact design, the sequential steps of which are presented in Table 16. The maximum determinant value is det $*=$ $8.960 \times 10^{-1}$ and it is associated with design class [5:0:0] having the design points $\{(-11,1-1,11,-1-1,-11)$ or $(-11,1-1,11,-1-1,1-1)$ or $(-11,1-1,11,-1-1,11)$ or $(-11,1-1,11,-1-1,-1)\}$. Within the class [3:1:1], the number of D-optimal exact designs is 4 .

Table 16. Combinatorics for a 5-point D-optimal exact design for model 3

\begin{tabular}{ccccccc}
\hline Step & $\mathrm{g}_{1}$ & $\mathrm{~g}_{2}$ & $\mathrm{~g}_{3}$ & $\begin{array}{l}\text { Number of Avail- } \\
\text { able Designs }\end{array}$ & $\begin{array}{l}\text { Best Determinant } \\
\text { Value }\end{array}$ & $\begin{array}{l}\text { Max Number of De- } \\
\text { signs to Investigate }\end{array}$ \\
\hline 0 & 3 & 1 & 1 & 16 & 0.2560 & 4 \\
1 & 3 & 2 & 0 & 24 & 0.4799 & 6 \\
2 & 3 & 0 & 2 & 4 & 0.1280 & 1 \\
3 & 4 & 1 & 0 & 4 & 0.7680 & 1 \\
4 & 5 & 0 & 0 & 4 & 0.8960 & 4 \\
5 & 2 & 3 & 0 & 24 & 0.3199 & 6 \\
6 & 2 & 2 & 1 & 36 & 0.1919 & 6 \\
\hline \multicolumn{2}{l}{ TOTAL } & \multicolumn{1}{l}{} \\
\hline
\end{tabular}

For $\mathrm{N}=6$, the initial tuple of support points is [3:2:1]. With this, we commence the search for the D-optimal exact design. From Table 17, the maximum determinant value is det $*=8.889 \times 10^{-1}$ and it is associated with design class [6:0:0] having the design points $\{(-11,1-1,11,-1-1,-11,1-1)$ or $(-11,1-1,11,-1-1,-11,11)$ or $(-11,1-1,11$, $-1-1,-11,-1-1)$ or $(-11,1-1,11,1-1,11)$ or $(-11,1-1,-11-1-1,1-1,-1-1)$ or $(-11,1-1,11,-1-1,11,-1-1)\}$.

Within the class [3:2:1], the number of D-optimal exact designs is 4.

Table 17. Combinatorics for a 6-point D-optimal exact design for model 3

\begin{tabular}{ccccccc}
\hline Step & $\mathrm{g}_{1}$ & $\mathrm{~g}_{2}$ & $\mathrm{~g}_{3}$ & $\begin{array}{l}\text { Number of Avail- } \\
\text { able Designs }\end{array}$ & $\begin{array}{l}\text { Best Determinant } \\
\text { Value }\end{array}$ & $\begin{array}{l}\text { Max Number of De- } \\
\text { signs to Investigate }\end{array}$ \\
\hline 0 & 3 & 2 & 1 & 24 & 0.4799 & 6 \\
1 & 3 & 3 & 0 & 16 & 0.4073 & 4 \\
2 & 3 & 1 & 2 & 16 & 0.1481 & 4 \\
3 & 4 & 1 & 1 & 4 & 0.4444 & 1 \\
4 & 4 & 2 & 0 & 6 & 0.6665 & 6 \\
5 & 5 & 1 & 0 & 16 & 0.7407 & 4 \\
6 & 6 & 0 & 0 & 6 & 0.8889 & 6 \\
7 & 2 & 3 & 1 & 24 & 0.1851 & 6 \\
8 & 2 & 4 & 0 & 6 & 0.2962 & 43 \\
\hline \multicolumn{7}{l}{ TOTAL } \\
\hline
\end{tabular}


For $\mathrm{N}=7$, the initial tuple of support points is [3:3:1]. With this, we commence the search for the D-optimal exact design as summarized in Table 18.

Table 18. Combinatorics for a 7-point D-optimal exact design for model 3

\begin{tabular}{ccccccc}
\hline $\begin{array}{l}\text { Step } \\
\mathrm{k}\end{array}$ & $\mathrm{g}_{1}$ & $\mathrm{~g}_{2}$ & $\mathrm{~g}_{3}$ & $\begin{array}{l}\text { Total Number of } \\
\text { Available Designs }\end{array}$ & $\begin{array}{l}\text { Best Determinant } \\
\text { Value }\end{array}$ & $\begin{array}{l}\text { Max Number of De- } \\
\text { signs to Investigate }\end{array}$ \\
\hline 0 & 3 & 3 & 1 & 16 & 0.2565 & 4 \\
1 & 3 & 4 & 0 & 4 & 0.3730 & 1 \\
2 & 3 & 2 & 2 & 24 & 0.1749 & 6 \\
3 & 4 & 3 & 0 & 4 & 0.5596 & 1 \\
4 & 5 & 2 & 0 & 24 & 0.6646 & 6 \\
5 & 6 & 1 & 0 & 24 & 0.7696 & 6 \\
6 & 7 & 0 & 0 & 4 & 0.9329 & 4 \\
7 & 2 & 5 & 0 & 24 & 0.2564 & 6 \\
8 & 2 & 4 & 1 & 6 & 0.1867 & 6 \\
\hline \multicolumn{2}{l}{ TOTAL } & \multicolumn{7}{c}{} \\
\hline
\end{tabular}

The maximum determinant value is $\operatorname{det} *=9.329 \times 10^{-1}$ and it is associated with design class [7:0:0] having the design points $\{(-11,1-1,11,-1-1,-11,1-1,11)$ or $(-11,1-1,11,-1-1,-11,11,-1-1)$ or $(-11,1-1,11,-1-1,-11,1-1$, $-1-1)$ or $(-11,1-1,11,-1-1,1-1,11,11,-1-1)\}$.

Within the class [3:3:1], the number of D-optimal exact designs is 4.

\subsection{Illustrations Using Model 4}

For the model

$$
y=\beta_{1} x_{1}+\beta_{2} x_{2}+\varepsilon
$$

we shall constuct $\mathrm{N}$-point $\mathrm{D}$-optimal exact design; $\mathrm{N}=2, \ldots, 4$.

For $\mathrm{N}=2$ the initial tuple of support points is [2:0:0]. With this, we commence the search for D-optimal exact design as summarized in Table 19.

Table 19. Combinatorics for a 2-point D-optimal exact design for model 4

\begin{tabular}{ccccccc}
\hline Step & $\mathrm{g}_{1}$ & $\mathrm{~g}_{2}$ & $\mathrm{~g}_{3}$ & $\begin{array}{l}\text { Total Number of } \\
\text { Available Designs }\end{array}$ & $\begin{array}{l}\text { Best Determinant } \\
\text { Value }\end{array}$ & $\begin{array}{l}\text { Max Number of De- } \\
\text { signs to Investigate }\end{array}$ \\
\hline 0 & 2 & 0 & 0 & 6 & 1.0000 & 6 \\
1 & 1 & 1 & 0 & 16 & 0.4998 & 4 \\
\hline \multicolumn{7}{l}{ TOTAL } \\
\hline
\end{tabular}

The maximum determinant value is det $*=1.0000$ and it is associated with design class [2:0:0] having the design points $\{(-11,1-1)$ or $(-11,11)$ or $(-11,-1-1)$ or $(1-1,11)$ or $(1-1,-1-1)$ or $(11,-1-1)\}$. Within the class $[2: 0: 0]$, the number of D-optimal exact design is 4 .

For $\mathrm{N}=3$, the initial tuple of support points is [2:1:0]. With this, we commence the search for D-optimal exact design as summarized in Table 20.

Table 20. Combinatorics for a 3-point D-optimal exact design for model 4

\begin{tabular}{ccccccc}
\hline Step & $\mathrm{g}_{1}$ & $\mathrm{~g}_{2}$ & $\mathrm{~g}_{3}$ & $\begin{array}{l}\text { Total Number of } \\
\text { Available Designs }\end{array}$ & $\begin{array}{l}\text { Best Determinant } \\
\text { Value }\end{array}$ & $\begin{array}{l}\text { Max Number of De- } \\
\text { signs to Investigate }\end{array}$ \\
\hline 0 & 2 & 1 & 0 & 24 & 0.8888 & 6 \\
1 & 2 & 0 & 1 & 6 & 0.4444 & 6 \\
2 & 3 & 0 & 0 & 4 & 0.8889 & 1 \\
3 & 1 & 2 & 0 & 24 & 0.8885 & 6 \\
4 & 1 & 1 & 1 & 16 & 0.2222 & 4 \\
\hline \multicolumn{7}{l}{ TOTAL } \\
\hline
\end{tabular}


The maximum determinant value is det $*=8.889 \times 10^{-1}$ and it is associated with design class [3:0:0] having the design points $\{(-11,1-1,11)$ or $(-11,1-1,-1-1)$ or $(-11,11,-1-1)$ or $(1-1,11,-1-1)\}$. Within the class $[2: 1: 0]$, the number of D-optimal exact design is 4 .

For $\mathrm{N}=4$, we have two starting designs, hence we demonstrate the search with the initial tuple of support points [2:1:1] and [3:1:0]. With tuple of support points [2:1:1] we commence the search for D-optimal exact design as summarized in Table 21a.

Table 21a. Combinatorics for a 4-point D-optimal exact design for model 4

\begin{tabular}{ccccccc}
\hline Step & $\mathrm{g}_{1}$ & $\mathrm{~g}_{2}$ & $\mathrm{~g}_{3}$ & $\begin{array}{l}\text { Total Number of } \\
\text { Available Designs }\end{array}$ & $\begin{array}{l}\text { Best Determinant } \\
\text { Value }\end{array}$ & $\begin{array}{l}\text { Max Number of De- } \\
\text { signs to Investigate }\end{array}$ \\
\hline 0 & 2 & 1 & 1 & 24 & 0.4999 & 6 \\
1 & 2 & 0 & 2 & 6 & 0.2500 & 6 \\
2 & 2 & 2 & 0 & 36 & 1.0000 & 9 \\
3 & 3 & 1 & 0 & 16 & 0.8749 & 4 \\
4 & 1 & 3 & 0 & 16 & 0.8746 & 4 \\
5 & 1 & 2 & 1 & 24 & 0.4998 & 6 \\
\hline \multicolumn{2}{l}{ TOTAL } & & 122 & & 35 \\
\hline
\end{tabular}

The maximum determinant value is $\operatorname{det} *=1.000$ and it is associated with design class [2:1:1] having the design points $\{(-11,11,01.414,1.4140)$ or $(-11,11,01.414,-1.414,0)$ or $(-11,11,1.4140,0-1.414)$ or $(-11,11,-1.414$ $0,0-1.414)$ or $(-11,-1-1,01.414,1.4140)$ or $(-11,-1-1,01.4140,-1.4140)$ or $(-11,-1-1,1.4140,0-1.414)$ or $(-11,-1-1,-1.4140,0-1.414)$ or $(1-1,11,01.414,1.4140)$ or $(1-1,11,01.414,-1.4140)$ or $(1-1,11,1.4140,0$ $-1.414)$ or $(1-1,11,-1.4140,0-1.414)$ or $(1-1,-1-1,01.414,1.4140)$ or $(1-1,-1-1,1.4140,-1.4140)$ or $(1-1,-1-1$, $1.4140,0-1.4140)$ or $(1-1,-1-1,-1.4140,0-1.414)\}$. Within the class [2:1:1], the number of D-optimal exact design is 16. Also with the tuple of support points [3:1:0] we commence the search for D-optimal exact design as summarized in Table $21 \mathrm{~b}$.

Table 21b. Combinatorics for a 4-point D-optimal exact design for model 4

\begin{tabular}{ccccccc}
\hline Step & $\mathrm{g}_{1}$ & $\mathrm{~g}_{2}$ & $\mathrm{~g}_{3}$ & $\begin{array}{l}\text { Total Number of } \\
\text { Available Designs }\end{array}$ & $\begin{array}{l}\text { Best Determinant } \\
\text { Value }\end{array}$ & $\begin{array}{l}\text { Max Number of De- } \\
\text { signs to Investigate }\end{array}$ \\
\hline 0 & 3 & 1 & 0 & 16 & 0.8749 & 4 \\
1 & 3 & 0 & 1 & 4 & 0.5000 & 1 \\
2 & 4 & 0 & 0 & 1 & 1.0000 & 1 \\
\hline \multicolumn{2}{l}{ TOTAL } & & 21 & & 6 \\
\hline
\end{tabular}

The maximum determinant value is det $*=1.0000$ and it is associated with design class [4:0:0] having the design points $\{(-11,1-1,11,-1-1)\}$. Within the class [4:0:0], the number of D-optimal exact design is 1 .

\subsection{D-Efficiency, G-Efficiency and Condition Number}

The D-efficiencies, G-efficiencies and condition numbers of the best $\mathrm{N}$-point designs for each model type have been evaluated and are presented in Table 22 . 
Table 22. D-efficiencies, G-efficiencies and condition numbers of the D-optimal exact designs

\begin{tabular}{llllllll}
\hline $\begin{array}{l}\text { Model } \\
\text { type }\end{array}$ & $\begin{array}{l}\text { Design } \\
\text { Size N }\end{array}$ & D-Optima & $\begin{array}{l}\text { Number of } \\
\text { Exact Designs }\end{array}$ & $\begin{array}{l}\text { Maximum } \\
\text { Variance of } \\
\text { Prediction }\end{array}$ & $\begin{array}{l}\text { D- } \\
\text { Efficiency }\end{array}$ & $\begin{array}{l}\text { G- } \\
\text { Efficiency }\end{array}$ & $\begin{array}{l}\text { Condition } \\
\text { Number }\end{array}$ \\
\hline Model 1 & 3 & 0.86 & 4 & 3.00 & 0.95 & 1.00 & 2.29 \\
& 4 & 1.00 & 1 & 3.00 & 1.00 & 1.00 & 1.00 \\
& 5 & 0.94 & 4 & 3.98 & 1.00 & 0.80 & 1.78 \\
& 6 & 0.92 & 8 & 3.34 & 0.97 & 0.90 & 2.46 \\
& 7 & 0.97 & 4 & 3.20 & 0.99 & 0.90 & 1.43 \\
\hline Model 2 & 2 & 1.00 & 4 & 2.00 & 1.00 & 1.00 & 1.00 \\
& 3 & 0.89 & 4 & 3.00 & 0.94 & 0.67 & 1.99 \\
& 4 & 1.00 & 1 & 2.00 & 1.00 & 1.00 & 1.00 \\
\hline Model 3 & 4 & 1.00 & 1 & 4.00 & 1.00 & 1.00 & 1.00 \\
& 5 & 0.82 & 4 & 5.00 & 0.95 & 0.80 & 2.50 \\
& 6 & 0.79 & 6 & 6.00 & 0.94 & 0.70 & 2.00 \\
& 7 & 0.85 & 4 & 7.00 & 0.96 & 0.60 & 2.50 \\
& 8 & 1.00 & 1 & 6.77 & 1.00 & 0.59 & 1.00 \\
& 9 & 0.94 & 4 & 4.50 & 0.98 & 0.90 & 1.75 \\
& 10 & 0.92 & 6 & 5.00 & 0.98 & 0.80 & 1.50 \\
& 11 & 0.94 & 4 & 5.50 & 0.98 & 0.89 & 2.24 \\
\hline Model 4 & 3 & 0.59 & 4 & 3.00 & 0.85 & 1.00 & 5.00 \\
& 4 & 1.00 & 1 & 3.00 & 1.00 & 1.00 & 1.00 \\
& 5 & 0.90 & 4 & 3.57 & 0.97 & 0.84 & 2.00 \\
& 6 & 0.89 & 6 & 4.00 & 0.97 & 0.75 & 2.00 \\
& 7 & 0.93 & 4 & 4.20 & 0.98 & 0.71 & 1.80 \\
\hline
\end{tabular}

\subsection{Graphs}

The contour plots, surface plots and fraction of design space graphs for the best $\mathrm{N}$-point $\mathrm{D}$-optimal exact designs are presented in this section. The pictorial presentations are for the intercept models 1 and 3. However since the D-optimal designs for the intercept models 1 and 3 are also, respectively, D-optimal for the no-intercept model 2 and 4 , the presentations similarly apply.

\subsubsection{Model 1}

The contour plot, surface plot and fraction of design space graph for the 4-point D-optimal exact design

$$
\xi_{4}=\left(\begin{array}{rr}
1 & 1 \\
1 & -1 \\
-1 & 1 \\
-1 & -1
\end{array}\right)
$$

are presented in Figure 3(a), 3(b) and 3(c) respectively. 


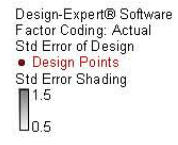

$X 1=A \cdot A$
$X 2=B: B$

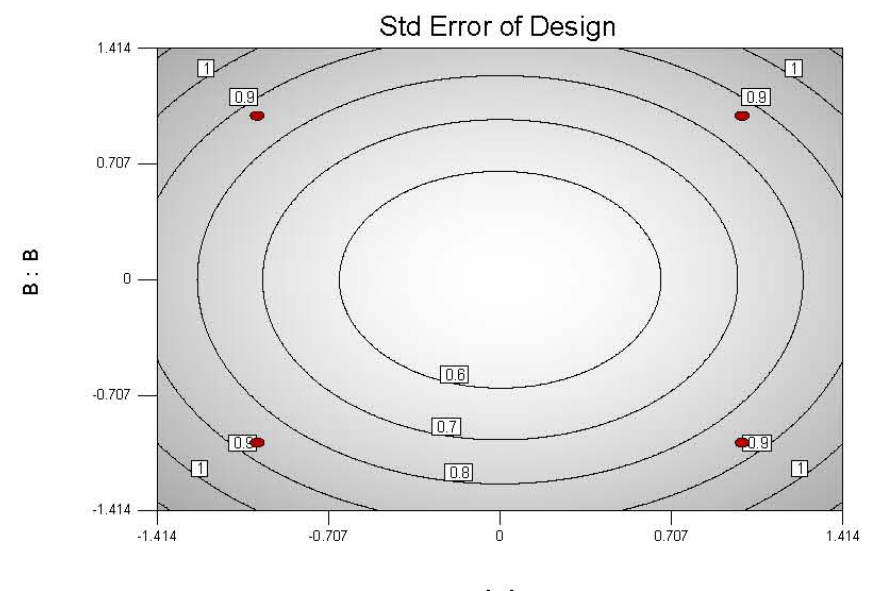

A: A

Figure 3(a). Contour plot for the 4-point D-optimal exact design using model 1

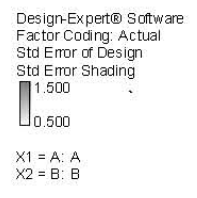

Fid Emor of Design

$X_{1}=A: A$
$X 2=B: B$

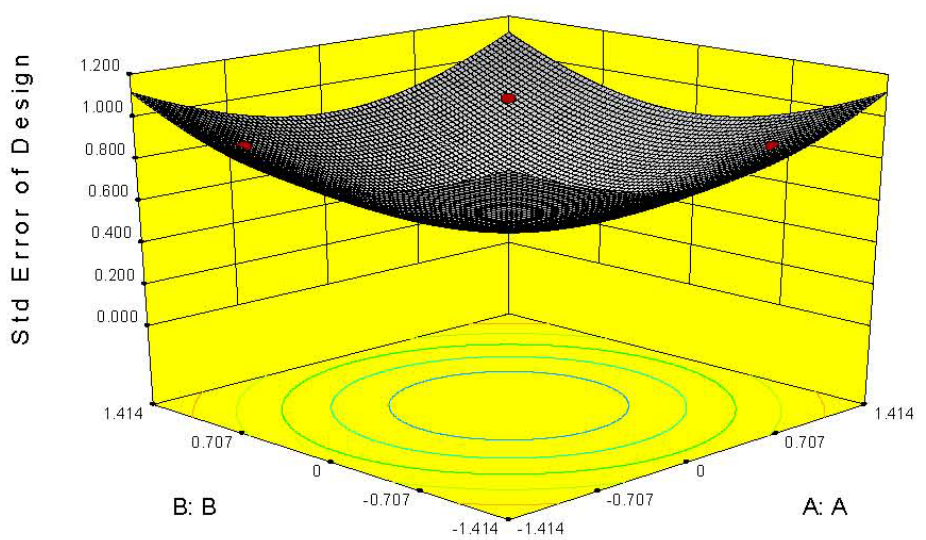

Figure 3(b). Surface plot for the 4-point D-optimal exact design using model 1

Design-Expert@ Software

Min Std Error Mean: 0.500

Avg Std Error Mean: 0.764

Max Std En
Cuboidal

radius $=1$
Points $=50000$

Points $=50000$
$t(0.05 / 2,1)=12.7062$

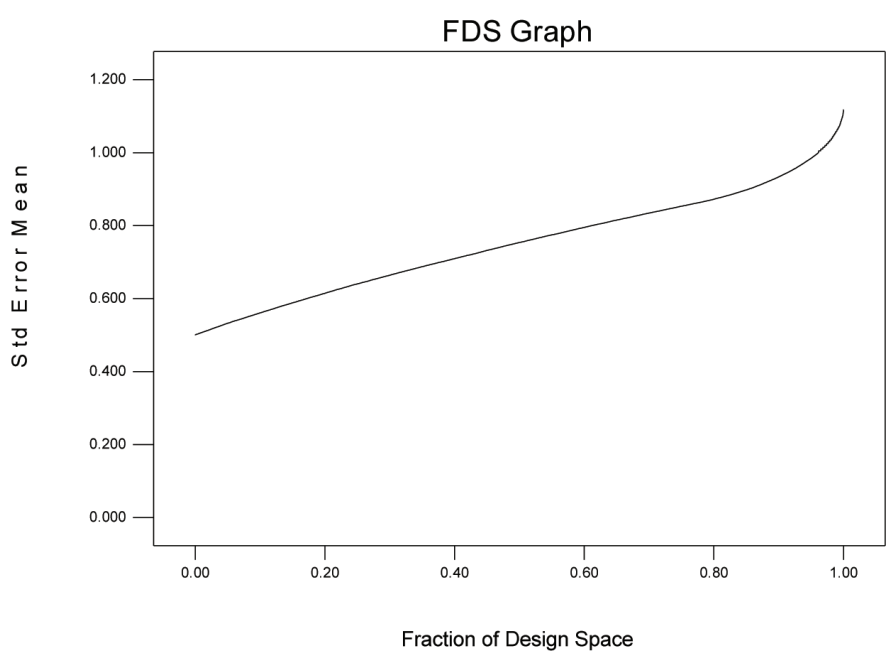

Figure 3(c). Fraction of design space graph for the 4-point D-optimal exact design using model 1 


\subsubsection{Model 3}

The contour plot, surface plot and fraction of design space graph for the 4-point D-optimal exact design

$$
\xi_{4}=\left(\begin{array}{rr}
1 & 1 \\
1 & -1 \\
-1 & 1 \\
-1 & -1
\end{array}\right)
$$

are presented in Figure 3(d), 3(e) and 3(f) respectively.
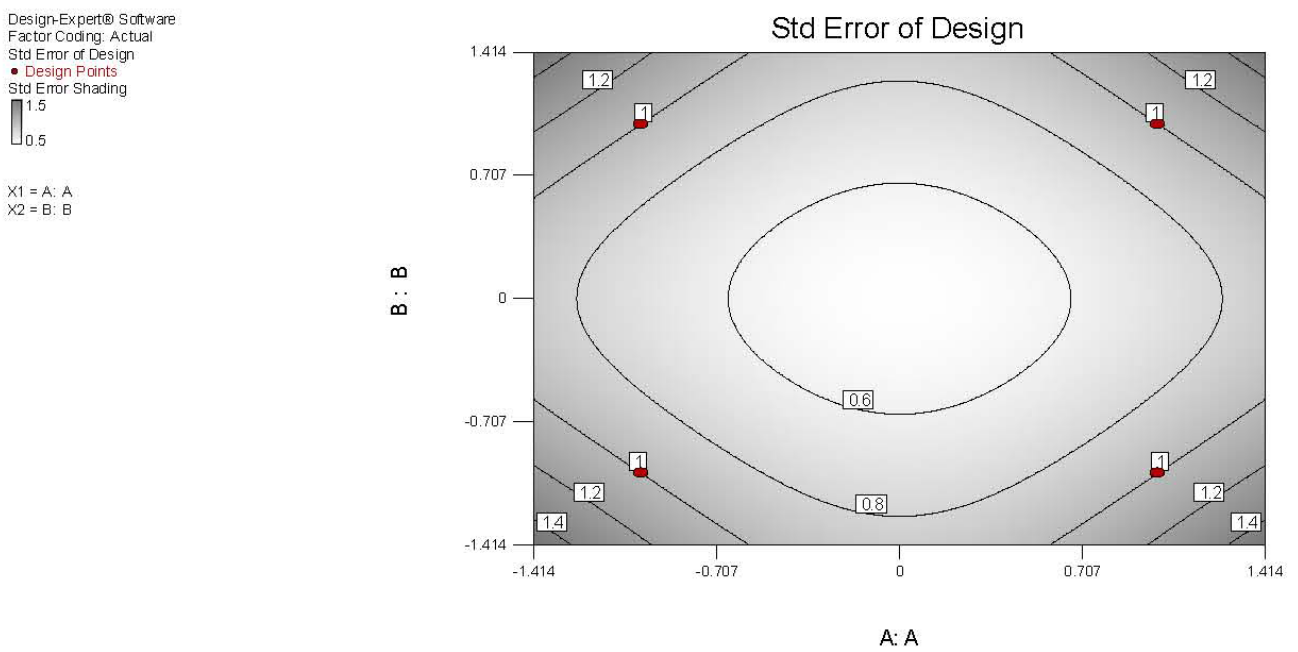

Figure 3(d). Contour plot for the 4-point D-optimal exact design using model 3
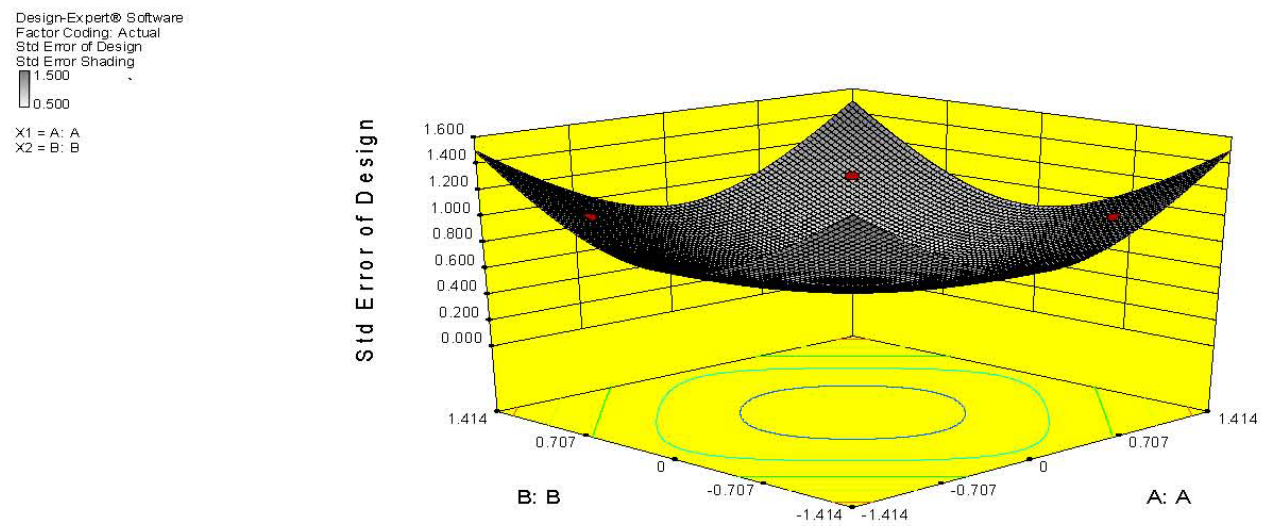

Figure 3(e). Surface plot for the 4-point D-optimal exact design using model 3 

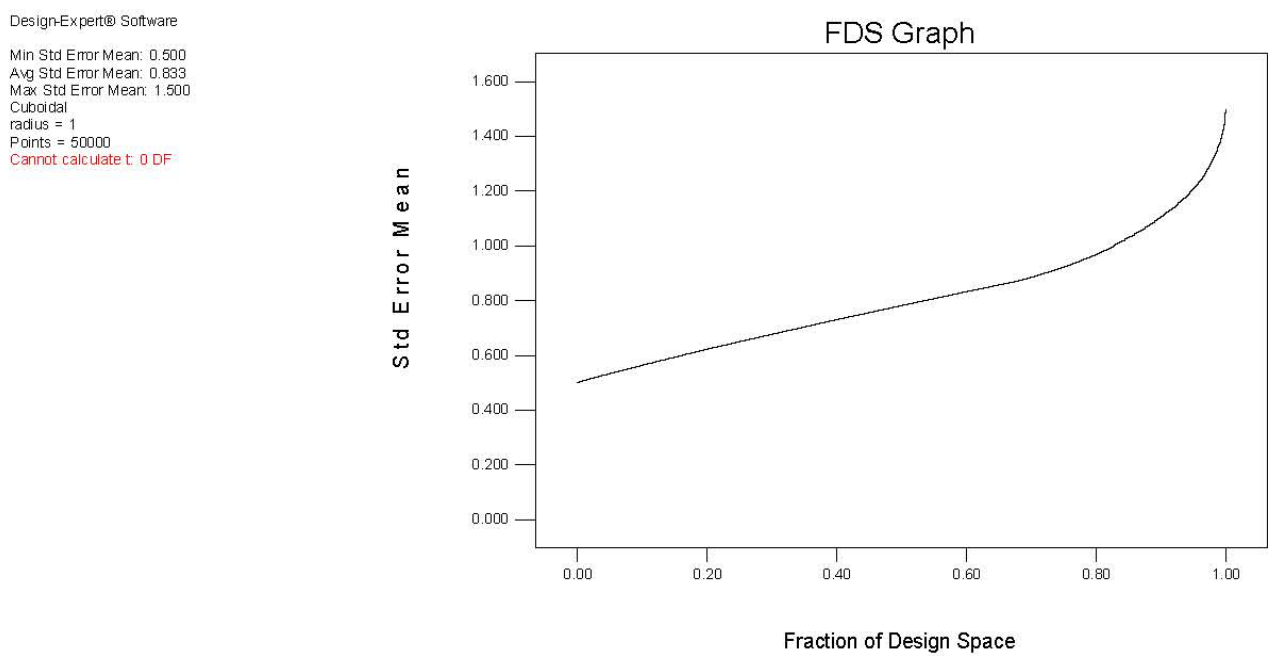

Figure 3(f). Fraction of design space graph for the 4-point D-optimal exact design using model 3

Similarly, the contour plot, surface plot and fraction of design space graph for the 8-point D-optimal exact design

$$
\xi_{8}=\left(\begin{array}{rr}
1 & 1 \\
1 & -1 \\
-1 & 1 \\
-1 & -1 \\
1 & 1 \\
1 & -1 \\
-1 & 1 \\
-1 & -1
\end{array}\right)
$$

are presented in Figure 3(g), 3(h) and 3(i) respectively.
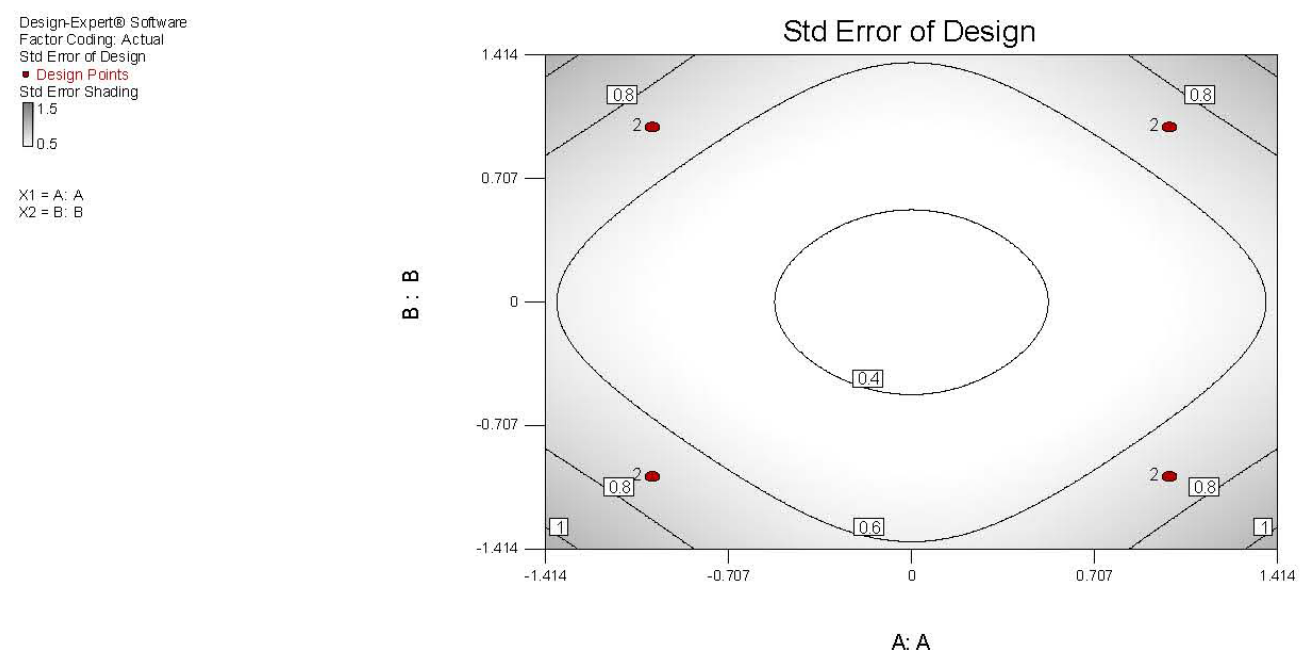

Figure 3(g). Contour plot for the 8-point D-optimal exact design using model 3 

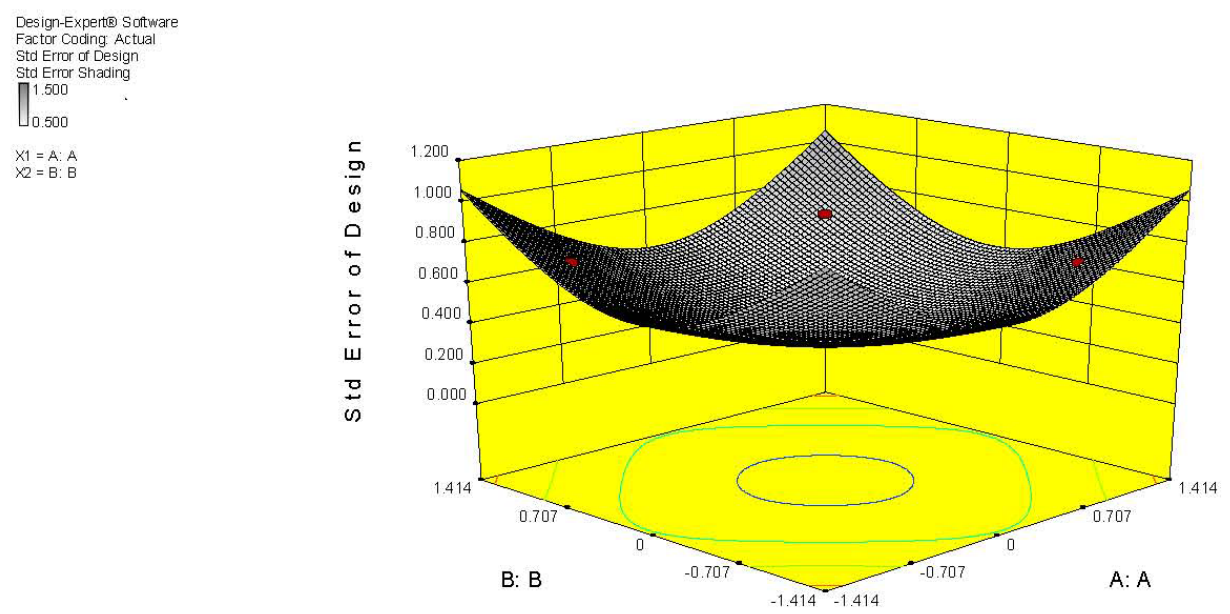

Figure 3(h). Surface plot for the 8-point D-optimal exact design using model 3
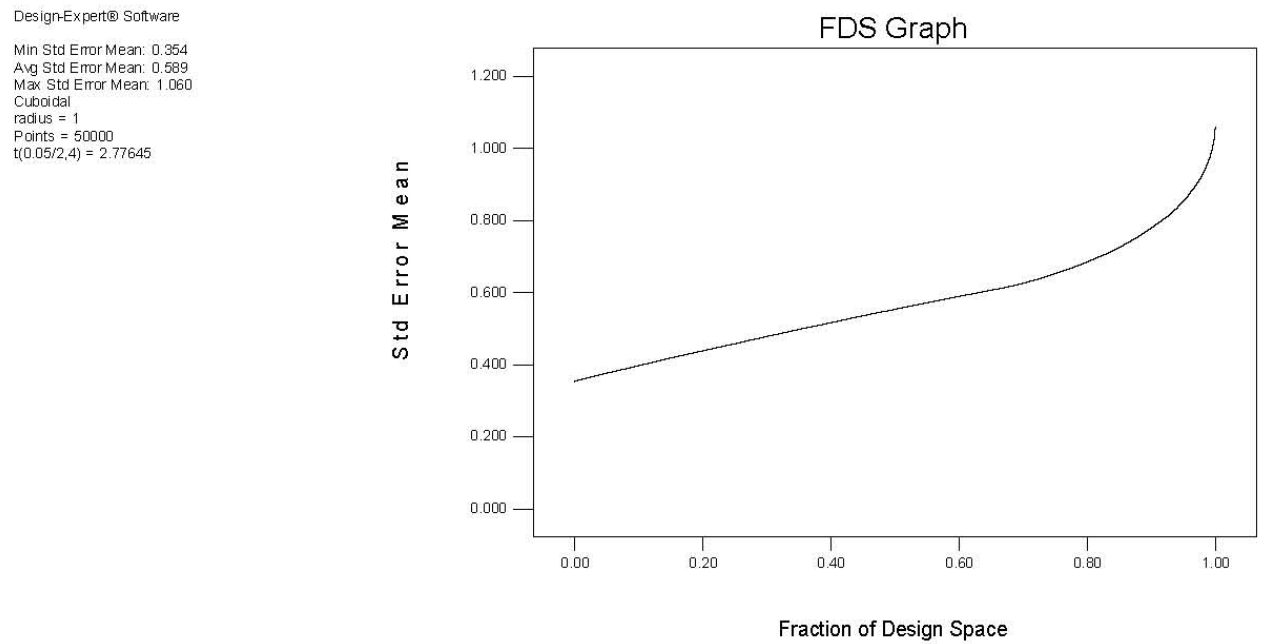

Figure 3(i). Fraction of design space graph for the 8-point D-optimal exact design using model 3

\section{Discussion}

Optimal designs allow model parameters to be estimated without bias and with minimum variance and are suitable for qualitative as well as quantitative models. Although most classical designs such as factorial designs assume the regression model is a full polynomial model, models with improper polynomial regression functions also exist. The flexibility of optimal design theory allows construction of optimal designs for polynomial regression functions having some terms missing.

The results of our investigation show that for model 1, a 4-point D-optimal exact design has its maximum determinant value of information matrix as 1.0000. A 5-point D-optimal exact design has its maximum determinant value of information matrix as $8.192 \times 10^{-1}$. A 6-point D-optimal exact design has its maximum determinant value of information matrix as $7.901 \times 10^{-1}$. A 7-point D-optimal exact design has its maximum determinant value of information matrix as $8.530 \times 10^{-1}$. An 8-point $\mathrm{D}$-optimal exact design has its maximum determinant value of information matrix as 1.0000. A 9-point D-optimal exact design has its maximum determinant value of information matrix as $9.364 \times 10^{-1}$. A 10 -point D-optimal exact design has its maximum determinant value of information matrix as $9.216 \times 10^{-1}$. An 11-point D-optimal exact design has its maximum determinant value of information matrix as $9.442 \times 10^{-1}$.

For the model 2, a 3-point D-optimal exact design has its maximum determinant value of information matrix as $8.633 \times 10^{-1}$. A 4-point D-optimal exact design has its maximum determinant value of information matrix 
as 1.0000. A 5-point D-optimal exact design has its maximum determinant value of information matrix as $9.433 \times 10^{-1}$. A 6-point D-optimal exact design has its maximum determinant value of information matrix as $9.193 \times 10^{-1}$. A 7-point D-optimal exact design has its maximum determinant value of information matrix as $9.735 \times 10^{-1}$.

For the model 3, a 3-point D-optimal exact design has its maximum determinant value of information matrix as $5.926 \times 10^{-1}$. A 4-point D-optimal exact design has its maximum determinant value of information matrix as 1.0000. A 5-point D-optimal exact design has its maximum determinant value of information matrix as $8.960 \times 10^{-1}$. A 6-point D-optimal exact design has its maximum determinant value of information matrix as 8.889 $\times 10^{-1}$. A 7-point D-optimal exact design has its maximum determinant value of information matrix as $9.329 \times 10^{-1}$.

For model 4, a 2-point D-optimal exact design has its maximum determinant value of information matrix as 1.0000 . A 3-point D-optimal exact design has its maximum determinant value of information matrix as $8.889 \times 10^{-1}$. A 4 point D-optimal exact design has its maximum determinant value of information matrix as 1.0000.

In each optimal design class, the best $\mathrm{N}$-point exact designs all have the same maximum variance of prediction. The designs also have the same D-efficiencies, G-efficiencies and condition numbers. The design size, $\mathrm{N}=4$, for all the models produced the best exact designs and are globally D-optimal designs. They further have the same D-efficiencies, G-efficiencies and condition numbers. The best N-point D-optimal design for the intercept model (model 1), is the same as the best N-point D-optimal design for the no-intercept model (model 3). This is as measured by the determinant values, D-efficiencies, G-efficiencies and Condition numbers. Similarly, the best $\mathrm{N}$-point D-optimal design for the intercept model (model 2) is the same as the best N-point D-optimal design in the no-intercept model (model 4). We further observe however, that other N-point designs constructed using the no intercept models had better determinant values than their corresponding intercept models.

The condition numbers which evaluate the sphericity and the symmetry of the D-optimal designs indicate that for model 1, the 4-point D-optimal exact design is orthogonal. For model 2, the 4-point D-optimal design is orthogonal. For model 3, the 4-point D-optimal exact design is orthogonal. For model 4, the 2-point D-optimal exact design and the 4-point D-optimal exact designs are orthogonal. Other $\mathrm{N}$-sized designs showed less orthogonality as the condition numbers exceed 1. The Equivalence of D-optimality and G-optimality is established for $\mathrm{N}=4$ under model 1 , for $\mathrm{N}=4$ under model 2 , for $\mathrm{N}=4$ under model 3 and for $\mathrm{N}=2$ and $\mathrm{N}=4$ under model 4 .

\section{References}

Albert-Udochukwuka, B. (2014). D-optimality: Properties and rules of construction (Unpublished M. Sc thesis). Department of Mathematics and Statistics, University of Port Harcourt, Nig.

Atkinson, A. C., \& Donev, A. N. (1992). Optimum experimental designs. New York, NY: Oxford University Press.

Bon, J. E. (2007). Generating exact D-optimal designs for polynomial model. SpringSim, 2, 121-126.

Box, G. E. P., \& Behnken, D. W. (1960). Some new three level designs for the study of quantitative variables. Technometrics, 2, 455-475. http://dx.doi.org/10.1080/00401706.1960.10489912

Eriksson, L., Johansson, E., Kettaneh-Wold, N., Wikstrom, C., \& Wold, S. (2000). Design of experiments: Principles and Applications. Learnways AB, Umea.

Huang, M. L., Chang, F., \& Wong, W. K (1995). D-optimal designs for polynomial regression without an intercept. Statistica Sinica, 5, 441-458.

Iwundu, M. P. (2010). On the choice of initial tuple of support points for quadratic response surface designs. African Journal of Physical Science, 3(2), 1-10.

Iwundu, M. P., \& Otaru, O. A. P. (2014). Imposing D-optimality criterion on the design region of the central composite designs. Scientia Africana, 13(1), 109-119.

Khuri, A. I., \& Cornell, J. A. (1987). Response Surfaces. New York: Marcel Dekker.

Montgomery, D. C. (1997). Design and analysis of experiments (4th ed.). New York: John Wiley and Sons.

Onukogu, I. B. (1997). Foundation of optimal exploration of response surfaces. Nsukka, Nigeria: Ephrata Press.

Onukogu, I. B., \& Iwundu, M. P. (2007). A Combinatorial Procedure for Constructing D-Optimal Designs. Statistica, 4, 415-423.

Wynn, H. P. (1970). The Sequential Generation of D-optimum Experimental Designs. Annuals Mathematical 
Statistics, 41, 1655-1664. http://dx.doi.org/10.1214/aoms/1177696809

\section{Copyrights}

Copyright for this article is retained by the author(s), with first publication rights granted to the journal.

This is an open-access article distributed under the terms and conditions of the Creative Commons Attribution license (http://creativecommons.org/licenses/by/3.0/). 